\title{
The microstructure of capsule containing self-healing materials: a micro-computed tomography approach
}

\section{Authors}

Jeroen Van Stappen ${ }^{1}$, Tom Bultreys ${ }^{1}$, Francisco A. Gilabert ${ }^{2}$, Xander K. D. Hillewaere ${ }^{3}$, David Garoz Gómez ${ }^{2}$, Kim Van Tittelboom ${ }^{4}$, Jelle Dhaene ${ }^{5}$, Nele De Belie ${ }^{4}$, Wim Van Paepegem², Filip E. Du Prez ${ }^{3}$ and Veerle Cnudde ${ }^{1}$

\section{Affiliations:}

1. UGCT/PProGRess, Dept. of Geology, Ghent University, Krijgslaan 281 S8, B-9000 Ghent, Belgium and SIM vzw, Technologiepark 935, B-9052 Zwijnaarde, Belgium

2. Mechanics of Materials and Structures, Ghent University, Technologiepark Zwijnaarde 903, B-9052 Zwijnaarde, Belgium

3. Polymer Chemistry Research Group, Department of Organic and Macromolecular Chemistry, Ghent University, Krijgslaan 281 S4-bis, B-9000 Ghent, Belgium

4. Magnel Laboratory for Concrete Research, Ghent University, Department of Structural Engineering, Ghent University, Technologiepark Zwijnaarde 904, B-9052 Ghent, Belgium

5. UGCT/Radiation Physics, Dept. of Physics and Astronomy, Ghent University, Proeftuinstraat 86, B9000 Ghent, Belgium

\section{Corresponding author:}

Jeroen Van Stappen, Jeroen.Vanstappen@ugent.be

Tel. 0032 (9) 2644684

Krijgslaan 281 S8, B-9000 Ghent, Belgium

\begin{abstract}
Extrinsic self-healing materials are materials with built-in (micro-) capsules or vessels, which upon fracturing release healing agents in order to recover the material's physical and mechanical properties. In order to better understand and engineer these materials, a thorough characterization of the materials' microstructural behaviour is essential and often overlooked. In this context, we illustrate how micro-computed tomography $(\mu \mathrm{CT})$ can be used to investigate the distribution and debonding of (micro-) capsules in their native state and in three dimensions in a polymer system with self-healing properties. Furthermore, we show how in-situ $\mu \mathrm{CT}$ experiments in a self-healing polymer and a selfhealing concrete system can elucidate the breakage and leakage behaviour of (micro-) capsules at the micrometre scale. While challenges related to image resolution and contrast complicate the characterization in specific cases, non-destructive 3D imaging with $\mu C T$ contributes to the understanding of the link between the microstructure and the self-healing behaviour of these complex materials.
\end{abstract}




\section{Keywords}

Self-healing

Capsules

$\mu C T$ imaging

Healing agent release

In-situ imaging

\section{Introduction}

\subsection{Self-healing materials}

Today, one of the main incentives in material engineering is damage prevention. This leads to the reinforcing and often overdesigning of the engineered materials in order to prolong their life span without damage. As a consequence, engineered materials are often overused, while the final product still requires regular inspection and maintenance [1]. A solution for these problems is found in the development of materials with a built-in repair mechanism, or so-called self-healing materials. These materials have the potential of being more reliable, since they are capable of repairing (in)visible, internal and/or external damage. This results in a longer lifetime of the material [2]. Self-healing materials have been a topic of intense research for over 15 years [3-5]. During that time, different types of self-healing approaches were developed and tested for their healing efficiency in different material classes. The approaches can be divided in two main categories: extrinsic self-healing, in which the healing agents are found in carriers added to the material, and intrinsic self-healing, for which the material exhibits self-healing properties due to its composition [1,6-8]. Extrinsic self-healing can be further classified based on the morphology of the healing agent's carrier. A first option is the sequestration of the self-healing agent in microcapsules, typically with a size ranging from $5 \mu \mathrm{m}$ (e.g. in coatings) to $150 \mu \mathrm{m}$ (e.g. in composites). Upon failure of the material, (micro-) capsules, are ruptured, releasing the self-healing agents into the region of damage. There, the healing agent reacts upon contact with moisture, air, or due to heating. Other agents react with a second component in the system, provided by the rupture of an additional type of capsules [7]. In the latter case, it is of course crucial for both components to be present in the area of damage in high enough quantities, so that the chemical reaction can take place [9]. A second extrinsic self-healing approach is the vascular based system in which the healing agent is found in a network of hollow tubes or capillaries connecting the interior of the material with the exterior part. At the moment of primary damage, the healing agents flow out of the damaged capillaries, after which the network may be refilled by an external source, allowing for multiple local healing events $[6,7]$.

Despite the significant efforts put into developing extrinsic self-healing materials, relatively little attention has been directed to the characterization of the spatial distribution of the healing agent's carrier in the material matrix. Yet, this can severely influence the material's self-healing efficiency. Furthermore, better characterization of samples prior to, during and after mechanical testing can offer more insight into the efficiency of the applied technology, notably into the mechanical behaviour of the carrier and the fluid mechanics of the self-healing agents released from these carriers. Although 
two dimensional (2D) analysis based on optical microscopy and scanning electron microscopy (SEM) offers the possibility to visualize fracture planes within different tested materials [10-13], carriers with healing agents can rupture subsequent to initial healing, during sample preparation for the SEM analysis.

High-resolution X-ray computed tomography $(\mu \mathrm{CT})$ is a non-destructive 3D technique, which allows to investigate the carriers without having to disturb their state by cutting the material or opening a fracture. Based on a set of two dimensional (2D) radiographs taken from different angles, the sample under investigation is digitally reconstructed in three dimensions (3D) [14]. This allows the investigation of the internal structures and processes in a broad range of materials. Due to the rapid evolution of this technique over the last few years, it has become a widely available tool in the field of material science $[15,16]$.

Despite the clear advantages of investigating extrinsic self-healing systems with $\mu \mathrm{CT}$, few studies have been undertaken [17-20]. In this work, we show how 2D and 3D analysis techniques can be combined in order to characterize distribution patterns of carrier systems in extrinsic self-healing materials, as well as the leakage of healing agents from these carriers after failure of the material. We emphasize on the experimental procedure and demonstrate the ability to adjust the set-up of experiments according to the visualization needs. The applied characterization workflows are invaluable to help predicting and explaining the efficiency of new self-healing material technologies.

\section{Materials \& Methods}

\subsection{Materials}

Two different self-healing materials, based on the extrinsic approach, are analysed: a polymer-based epoxy material, with self-healing properties due to the inclusion of microcapsules, and concrete, with self-healing properties obtained by embedded tubular capsules. For both cases, it is important to understand the distribution of healing agents in the material as well as the release of these agents upon failure.

\subsubsection{Self-healing polymers Epoxy matrix}

The commercial epoxy based on EPON 828 resin and DETA hardener has been used to build the selfhealing materials. The synthesis and mechanical properties of these epoxy are well known and it is usually used as reference in self-healing [21].

\section{Healing agents: Thiol-isocyanate capsules}

A fast healing system was developed by Hillewaere et al. (2014), in which the healing agents are a tetrafunctional thiol-methyl benzoate mixture (TetraThiol) and multifunctional hexamethylene diisocyanate isocyanurate trimer $\left(\mathrm{HDI}_{3}\right)$ in a 1:1 ratio (Figure 1 ). Reaction of these chemicals results in the formation of strong polythiourethane-based networks, causing self-healing of the epoxy matrix. This system was developed to tackle some disadvantages of previously developed systems: the healing agents used in this system are low in toxicity, thermally stable and inexpensive [22]. At the same time, the reaction is efficient in the presence of moisture and air. 


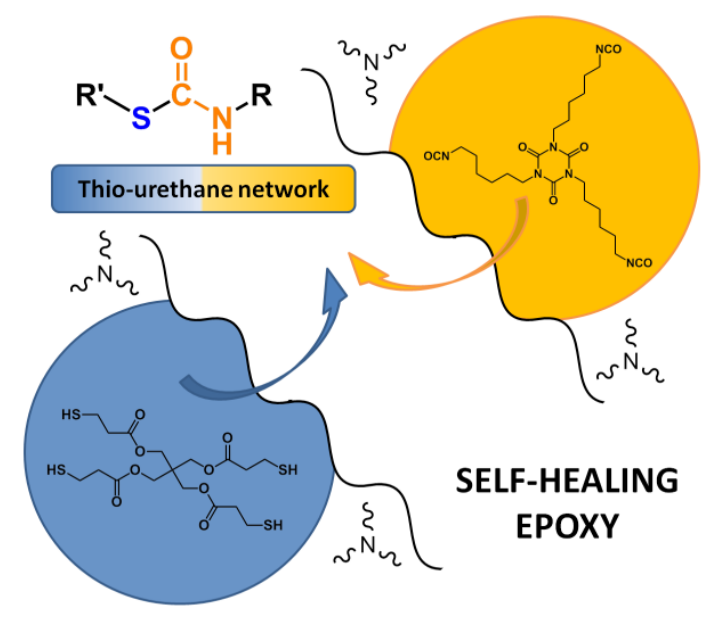

Figure 1: Thiol-icocyanate chemistry, applied for self-healing epoxy materials. TetraThiol-containing microcapsules (down left), combine with $\mathrm{HDI}_{3}$-containing capsules, catalysed by a tertiary amine, to result in polythiourethane-based networks, necessary for the self-healing processes. Copyright Wiley-VCH Verlag $\mathrm{GmbH} \& \mathrm{Co}$. KGaA. Reproduced with permission of Advanced Functional Materials [22].

Microcapsules with melamine-formaldehyde walls, containing TetraThiol in the core were prepared following the procedure reported by Yuan et al. (2008), while the polyurea microcapsules with $\mathrm{HDI}_{3}$ in the core were made by interfacial polymerization [23]. A detailed description of the synthesis of these microcapsules is found in Hillewaere et al. (2014). Through laser diffraction, using a Beckman Coulter LS 200 instrument, the authors determined the size distributions of both capsule types after they were sieved over a $500 \mu \mathrm{m}$ mesh. This size distribution was also confirmed through scanning electron microscopy (SEM). Both capsule types had a mean diameter of around $150 \mu \mathrm{m}$.

\section{Chemical adaptation of epoxy matrix for enhanced visualisation}

To investigate the 3D microcapsule distribution in an epoxy matrix, a mixture of the TetraThiol- and $\mathrm{HDI}_{3}$ microcapsules was dispersed into EPON 828 epoxy resin and DETA hardener prior to curing of the epoxy resin. The combination of the EPON 828 epoxy and DETA hardener was chosen because of the known catalytic effect of the epoxy matrix on the thiol-isocyanate reaction and promising healing efficiencies obtained in a previous study [22]. The Tapered Double Cantilever Beam (TDCB) test, with the protocol proposed by Brown et al. (2002) [24], was performed prior to X-ray CT scanning to test the (mechanical) healing efficiency of the system. In this test, a crack is induced in the material by pulling apart both sides of the TDCB sample. The microcapsules were only added to the EPON 828 material around the symmetric plane along which the crack propagation is expected. In order to avoid a deviation of the crack out of the symmetric plane, TDCB samples with an initial groove along this plane were used (Figure 2). The TDCB samples were subsequently pre-cracked using a fresh razor blade following the ASTM D4045 standard. After this, the epoxy material with the embedded microcapsules was loaded until the crack reached a visible length, avoiding the complete fracture of the TDCB sample. Then, the sample was unloaded and removed from the tensile machine. Holding the two legs of the TDCB sample gently together ensured the crack surfaces to stay in contact. After a healing period of 5 days at $25^{\circ} \mathrm{C}$, the fracture toughness was measured once more. The healing efficiency was calculated as the ratio between the fracture toughness measured in the healed specimen and the one from the original. Both parts of the TDCB sample could then be scanned by X-ray micro-CT, permitting to 
investigate the effect of crack formation on the microcapsules at the crack surface, as well as the 3D distribution of microcapsules in the matrix.

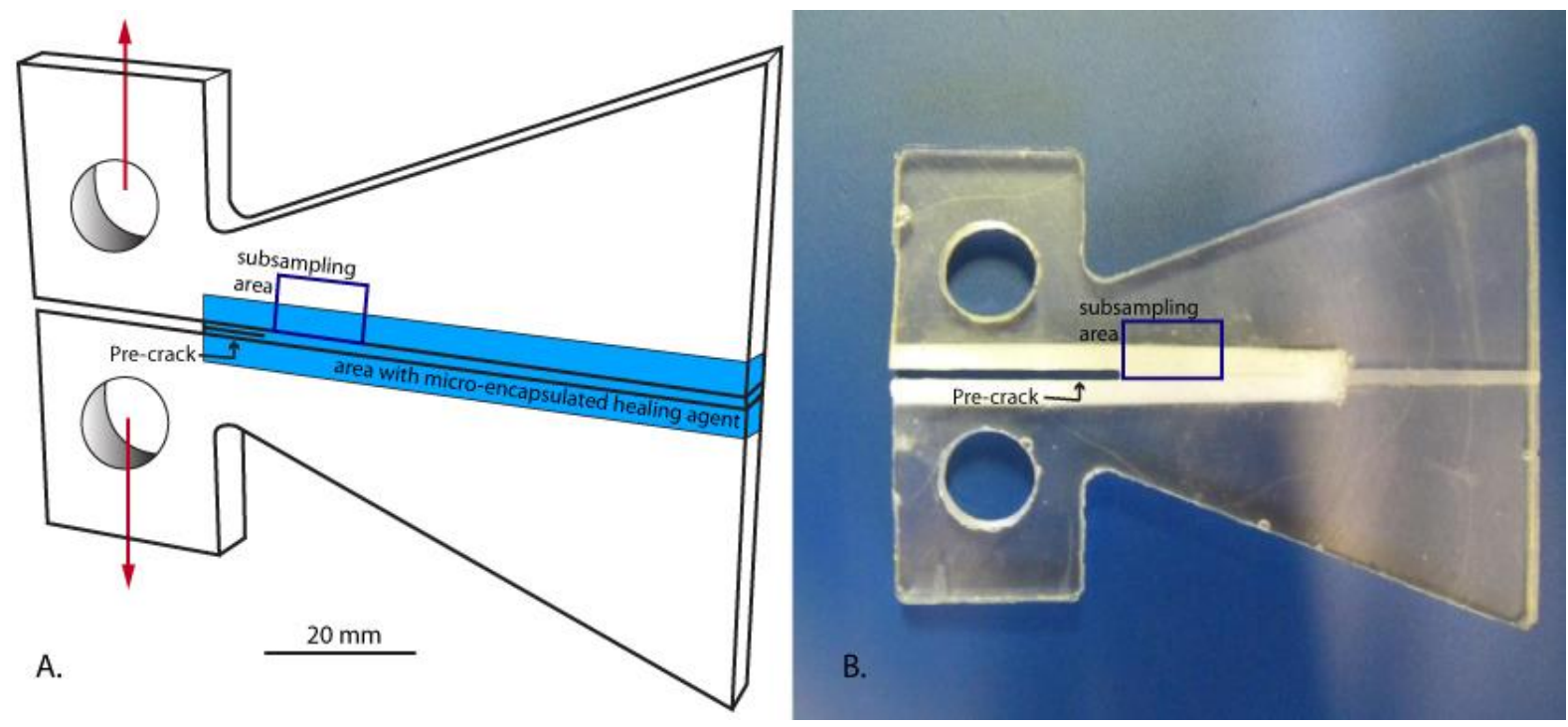

Figure 2: A) Schematic representation of a TDCB sample in which the light blue area represents the part of the sample containing microcapsules. The pre-crack in the middle part is indicated and will ensure that the induced crack will form in the area with embedded microcapsules. After the sample has been loaded until fracture, by applying a tensile stress in the direction of the red arrows, a small subsample (blue box) is taken from this area for $\mu C T$ imaging. B) illustrates the real life version of this TDCB sample.

In a second test, the epoxy matrix was changed to a partially brominated epoxy material. Doing so, the $\mathrm{X}$-ray attenuation, which is the reduction of the intensity of the X-ray beam as it traverses matter [16], dependent on the material as well as the energy at which is scanned, was slightly changed for the matrix. Changing the epoxy matrix thus leads to an enhancing difference in X-ray attenuation, by the matrix on the one hand and the two types of microcapsules on the other hand. This is important, as it determines the contrast between these three materials in the $\mu \mathrm{CT}$ images. For the synthesis of this brominated material, 20 wt\% of the EPON 828 was replaced by the epoxy resin EPON 1163 (Figure 3), which is a typical flame retardant additive used in standard epoxy materials.<smiles>CC(C)(c1cc(Br)c(OCC2CO2)c(Br)c1)c1cc(Br)c(OCC2CO2)c(Br)c1</smiles>

Figure 3: Chemical structure of the epoxy resin EPON 1163.

\section{Leakage experiments}

In a third test, the leakage of healing agents in a fracture in the epoxy matrix was visualized with $\mu \mathrm{CT}$. In order to enhance the leakage visualization, these experiments were carried out on small epoxy samples, only containing TetraThiol microcapsules. The samples had a cylindrical shape, with a diameter of $6 \mathrm{~mm}$ and height of $10 \mathrm{~mm}$, and contained either 5, 10 or $15 \mathrm{wt} \%$ of microcapsules. The samples had a small pre-crack, made with a fresh razor blade. Prior to the induction of a fracture within these samples, the distribution of the microcapsules within them was analysed with micro-CT. Subsequently, the razor blade was placed within the precrack, after which a crack was induced through 
a slight tap on the blade, as illustrated in Figure 4. Applying these steps to epoxy samples with different contents of microcapsules allows a visual comparison of the outflow patterns from the capsules within the newly formed crack.

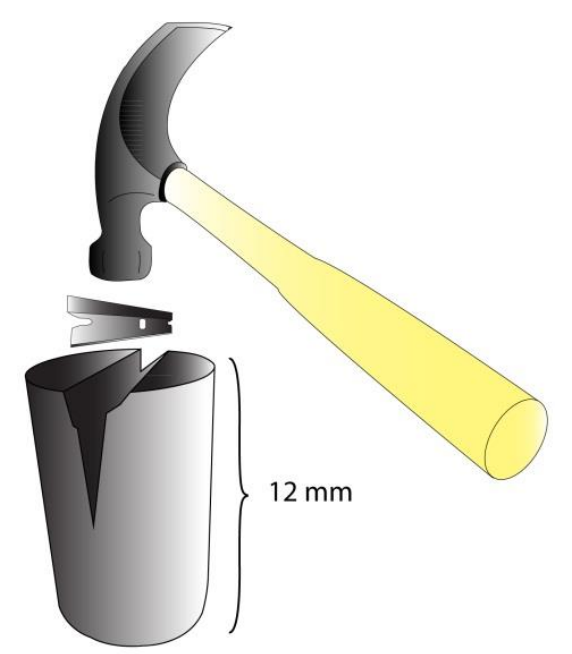

Figure 4: Visualisation of the leakage experiment in epoxy samples.

Samples in which the crack propagated throughout the entire sample, and thus the two halves of the sample were physically separated from each other, were discarded from analysis. In this way, leakage of healing agents out of the microcapsules could be analysed with relevance to healing of a microcrack within a larger body of epoxy matrix.

\subsubsection{Self-healing concrete}

\section{Concrete matrix}

Two concrete cubes with dimensions of $60 \mathrm{~mm} \times 60 \mathrm{~mm} \times 60 \mathrm{~mm}$, obtained from concrete prisms of $150 \mathrm{~mm} \times 150 \mathrm{~mm} \times 600 \mathrm{~mm}$, were used for experiments in which the outflow of healing agents from tubular glass capsules was investigated. The exact concrete composition, with a water to cement ratio of 0.5 , is shown in table 1 .

Table 1: Concrete composition.

\begin{tabular}{|l|l|}
\hline \multirow{2}{*}{ Constituent } & Amount \\
\cline { 2 - 2 } & {$\left[\mathrm{kg} / \mathrm{m}^{\mathbf{3}}\right]$} \\
\hline Sand 0/4 & 670 \\
\hline Gravel 2/8 & 490 \\
\hline Gravel 8/16 & 790 \\
\hline CEM I 52.5 N & 300 \\
\hline Water & 150 \\
\hline
\end{tabular}

The average concrete strength and density were measured on $150 \mathrm{~mm} \times 150 \mathrm{~mm} \times 150 \mathrm{~mm}$ concrete cubes. After casting the prisms and cubes, they were stored in an air conditioned room at a temperature of $20^{\circ} \mathrm{C}$ and a relative humidity of more than $90 \%$. One day after casting, the prisms were demoulded and stored under water until the age of 21 days after which they were stored again in the 
above mentioned air-conditioned room $\left(20^{\circ} \mathrm{C},>90 \%\right)$. Average strength and density of the concrete at the age of 28 days amounted to $48.5 \mathrm{~N} / \mathrm{m}^{2}$ and $2376 \mathrm{~kg} / \mathrm{m}^{3}$, respectively.

\section{Healing agent}

The healing agent was brought into the concrete matrix through tubular glass capsules, allowing to trigger the healing action. Borosilicate glass tubes, purchased from Hilgenberg - GMBH, Frankfurt, Germany, were filled with the healing agent MEYCO MP 355 1K (MEYCO), purchased from BASF, Belgium. The choice of this healing agent, which is commercially used to make cracks watertight and to cut off running water, was based on the positive outcome of earlier research [18]. MEYCO consists of two compounds, with a viscosity of $320 \mathrm{mPa} . \mathrm{s}$ and $70 \mathrm{mPa} . \mathrm{s}$ at $23^{\circ} \mathrm{C}$, respectively. The first compound is a prepolymer of polyurethane, which starts foaming in moist surroundings. The second compound is an accelerator, shortening the reaction time. The foaming reaction of this healing agent leads to an increase in volume with a factor of 25 to 30 . In each concrete sample, two glass tubes with an outer diameter of $3 \mathrm{~mm}$ were inserted: one filled with the prepolymer and the other filled with a mixture of accelerator and water. First, the tubes were sealed with polymethylmethacrylate at one end, after which the tubes were filled with the components of the healing agent, injected with a syringe. When the tubes were filled, the other ends were sealed and they were introduced into the holes (see further) of the concrete cubes. Inside the cubes, the tubes filled with each of the components were positioned next to each other.

\section{Leakage experiments}

As mentioned before, from the original concrete prisms, cubes with dimensions of $60 \mathrm{~mm} \times 60 \mathrm{~mm} \times$ $60 \mathrm{~mm}$ were sawn. These cubes were cut into two prisms with a width of $40 \mathrm{~mm}$ and $20 \mathrm{~mm}$, respectively. The latter sawing faces and the bottom faces of the prisms were polished so that both parts fitted well when placed against one another, as shown in Figure 5. Both prisms were clamped together with a certain inner distance called 'crack opening distance', or COD, and with a difference in height of $2 \mathrm{~mm}$. The COD was controlled by using calibrated spacers of $300 \mu \mathrm{m}$ thick. This separation corresponds to a typical distance between the faces of a crack inside concrete [18]. Two holes with a diameter of $3 \mathrm{~mm}$, going through each of the prisms, were drilled next to each other. In these holes, the glass tubes with the healing agents were placed. With a slight tap on the concrete prism emerging above the other, both glass tubes are broken so that, due to capillarity, the encapsulated healing agent and accelerator are able to flow out, into the idealized crack. A paper describing the original idea of this set-up is currently submitted.

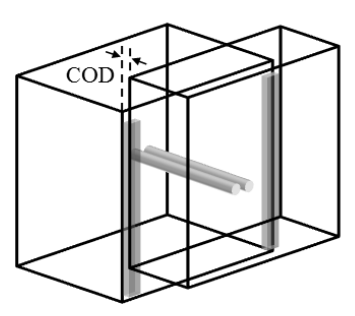

Initial position

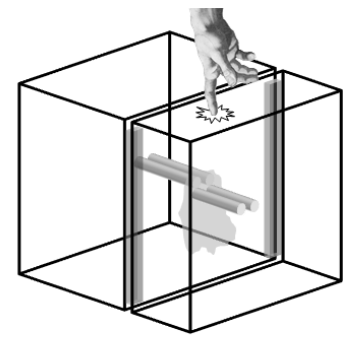

Capsule breakage

Figure 5: Schematic representation of the leakage experiments in the concrete samples. $C O D=$ crack opening distance. 


\subsection{Methods}

\subsection{1. $\quad \mu C T$ visualization and analysis}

For X-ray Computed Tomography analysis, the samples of interest are placed on a rotating stage between an X-ray source and an X-ray detector. The X-rays, emitted from the source, pass through the materials and interact with them by photo-electric absorption and scattering, thereby decreasing the intensity of the X-rays. This decrease is material and energy dependent and is described by the linear attenuation coefficient $\mu$ of the material. The resolution which can be obtained with $\mathrm{CT}$ imaging is limited by certain hardware properties, such as the (pixel) size of the detector, and the spot size of the $\mathrm{X}$-ray source. Due to the conical shape of the X-ray beam in $\mu \mathrm{CT}$ scanners, the magnification of the scan can be tuned by decreasing the source-sample distance or increasing the source-detector distance. However, the latter also reduces the image quality by decreasing the X-ray flux on the detector. Therefore, it is more beneficial to image smaller samples placed closer to the X-ray source to obtain a larger magnification of the sample (and thus resolution of the obtained images) $[16,25]$. In the following experiments, sample size is thus an important parameter, which can be adapted so that the intended resolution is obtained.

The scanners used in this study, as well as the data acquisition and reconstruction software packages, are developed by Ghent University's Centre for X-ray Tomography (UGCT) [14,26-28]. Two different $X$-ray $\mu C T$ scanners were used in this research. Scans for the analysis of the distribution of microcapsules in polymers were primarily made with a directional open-type Feinfocus tube as X-ray source and a Varian $2520 \mathrm{~V}$ Paxscan detector [28].

Experiments in which leakage from carrier systems (both microcapsules in epoxy and tubular glass capsules in concrete) were analysed, were carried out on the HECTOR (High Energy CT scanner Optimized for Research) set-up [27]. On this scanner, which was developed in collaboration with the company X-Ray Engineering, Belgium, a XWT 240-SE microfocus X-ray source and a large PerkinElmer flat panel detector are installed. This equipment allows scanning of samples with a high total X-ray absorption (requiring a high X-ray energy and flux to obtain a sufficient signal-to-noise ratio at the detector) as well as performing high resolution scans down to approximately $3 \mu \mathrm{m}$ resolution. Therefore, this set-up is particularly well suited for the experiments in which leakage of healing agents is investigated in concrete blocks, since these experiments require the use of high-energy X-rays (up to $220 \mathrm{kV}$ ).

In the experiments, the sample size of the sample under investigation was chosen according to the resolution needed to differentiate the carrier systems of the healing agents. In the case of the polymer samples, with capsule size around $150 \mu \mathrm{m}$, subsamples with a diameter of approximately $10 \mathrm{~mm}$ were taken from the TDBC samples. These scans were performed by acquiring 1800 projection images with an exposure time of $2000 \mathrm{~ms}$ at an X-ray source accelerating voltage of $100 \mathrm{kV}$ and $9 \mathrm{~W}$ output power. The tomographs were reconstructed with the Octopus Reconstruction software [14] (Inside Matters, Belgium). The source-sample distance of $34.3 \mathrm{~mm}$ and source-detector distance of $862.8 \mathrm{~mm}$ resulted in a reconstructed voxel size of $5.0 \mu \mathrm{m}$. This ensured that the obtained resolution and image quality were high enough to visualize individual microcapsules. In the case of self-healing concrete, the healing agent is embedded in glass capsules, from which the agents are released in a crack with a COD of 300 $\mu \mathrm{m}$. The $\mu \mathrm{CT}$ set-up described above allows this to be monitored with a resolution high enough to differentiate the healing agents and the crack in the $60 \times 60 \times 60 \mathrm{~mm}$ concrete blocks. These $\mu \mathrm{CT}$ scans 
were performed with 2400 projections with an exposure time of $999 \mathrm{~ms}$ each, an X-ray source accelerating voltage of $220 \mathrm{kV}$ and an output power of $45 \mathrm{~W}$. The source-sample distance of $273.5 \mathrm{~mm}$, in combination with the source-detector distance of $1166.0 \mathrm{~mm}$ resulted in a reconstructed voxel size of $46.3 \mu \mathrm{m}$.

In order to analyse the leakage from the carrier systems (both microcapsules and tubular glass capsules), two micro-CT scans were made for each leakage experiment: one before and one after leakage. The combination of both scans allows differential imaging of the samples [29,30], allowing to better visualize the outflow of the liquids. The 3D attenuation based rigid body registration algorithm from the DataViewer software package (Bruker microCT) was used to match the 3D CT datasets before and after the crack was induced. The differential images were subsequently analysed using Octopus Analysis, formerly called Morpho+ [26]. Segmentation of the different material phases in the scans were performed by grey value thresholding in Octopus Analysis. The software package VGStudio ${ }^{\circledR}$ MAX was then used for the 3D visualization of this data.

\section{Results \& Discussion}

\subsection{Chemical adaptation of epoxy matrix for enhanced visualisation}

In an extrinsic self-healing system, the healing efficiency depends on different parameters such as the (micro-)capsule spatial distribution, the fracture behaviour of both microcapsules and the matrix, the flow and mixing of the healing agents in the crack and the resulting healing agent volume delivered to the crack [22]. These parameters need to be measured in 3D to fully characterize the system. Thus, traditional techniques such as SEM analysis do not fully capture them. Furthermore, 2D techniques often require destructive sampling to expose the surface for visualization, making it difficult or even impossible to observe the capsules in their native state.

The $\mu \mathrm{CT}$ experiments allowed to visualize the 3D distribution of microcapsules, which influences both the self-healing efficiency and the initial mechanical properties of the material. Indeed, coagulation of the capsules will impact the probability that the two agents will mix when the material is fractured, since it influences the fracturing behaviour of the microcapsules. The presence of microcapsules has the tendency to strengthen the material due to hackle markings and sub-surface micro-cracking [21]. Figure 6 shows 3 different arrangements of capsules: strongly coagulated (A), lightly coagulated (B) and homogeneously spread (C).

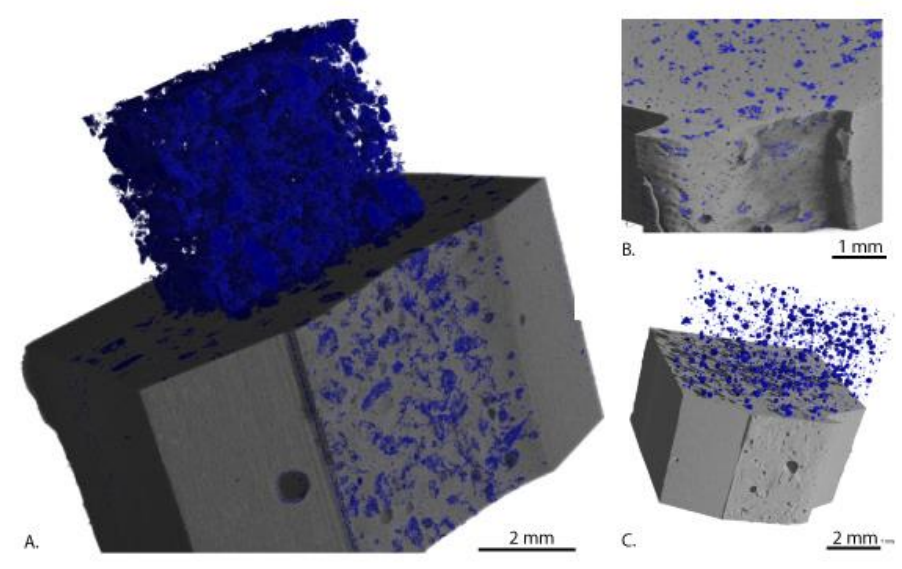


Figure 6. Self-healing polymer samples cut from a TDCB-geometry. On these figures, both the crack geometry as the capsule distribution can be investigated. Sample A (sample 201) has strongly coagulated capsules, sample B (sample 360) has lightly coagulated capsules, while sample C (sample 127) has homogeneously spread capsules.

The $\mu C T$ measurements are very useful to investigate the adhesion of the capsules to the matrix. This adhesion is crucial to prevent the debonding of microcapsules from the epoxy matrix. In Figure 7, debonding of $\mathrm{HDl}_{3}$-capsules can be observed within the bulk of the sample. This observation would be difficult to make with SEM or microscopy measurements, as it would require cutting the sample. Debonding of capsules is an important issue, as it inhibits breakage of capsules during material failure, reducing the healing efficiency. Figure 8 shows debonding of capsules at the fracture surface after performing a TDCB test. Digitally cutting through the sample demonstrate that the debonded capsules contain $\mathrm{HDI}_{3}$ rather than TetraThiol, as the TetraThiol capsules have a higher X-ray attenuation coefficient than the matrix, and thus are highlighted brighter in the scans (tagged red in the rendering, Figure 8).

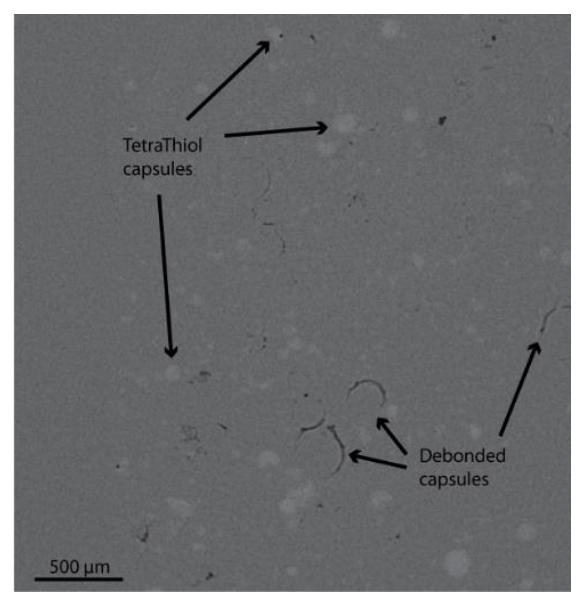

Figure 7. Spherical edges in this self-healing polymer sample show debonding of capsules with the same attenuation coefficient as the polymer matrix. The lighter grey values are TetraThiol capsules.

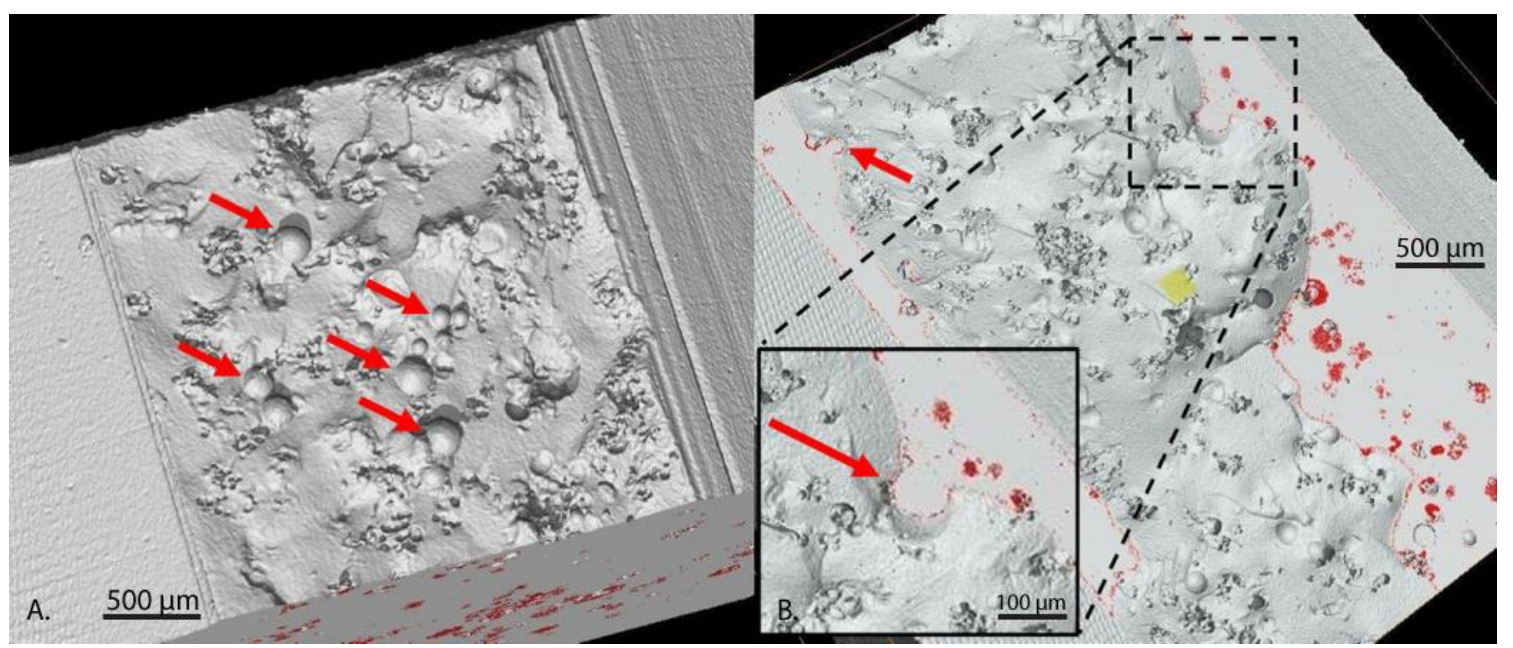

Figure 8. Debonded capsules (indicated with arrows) on the crack surface of a fractured TDCB sample containing two types of capsules. The $3 \mathrm{D}$ nature of $\mu \mathrm{CT}$ images allows to cut through the protruding capsules, showing they have a grey value close to that of the matrix. This allows to identify the debonded capsules as $\mathrm{HDI}_{3}$ capsules rather than TetraThiol capsules, which attenuate $\mathrm{X}$-rays more strongly (tagged red in the rendering).

In order to be able to differentiate the $\mathrm{HDI}_{3}$-containing microcapsules from the polymer matrix, TDCB samples were prepared in which 20 wt\% of EPON 828 was replaced by EPON 1163 (see material 
section). Using the XCOM web database of the National Institute of Standards and Technology (NIST), USA, the total attenuation coefficient $\mu$ of each of the components in the experiment can be plotted for different $\mathrm{X}$-ray energies (Figure 9). This display shows the different components of the experiments carried out. Scans were carried out at with an X-ray source accelerating energy of $100 \mathrm{kV}$, in order to penetrate the object. At this energy, the figure shows that the total linear attenuation coefficient for the EPON 828 matrix and the $\mathrm{HDI}_{3}$-capsules are almost coinciding. They are only slightly lower than the linear attenuation coefficient of the TetraThiol-capsules. When comparing the mixture of the EPON 828 and the EPON 1163 epoxy (in the correct weight ratio) with the $\mathrm{HDI}_{3}$ - and TetraThiol-capsules, the difference between the matrix and the capsules becomes more distinguishable. However, both types of capsules remain characterized by a very comparable linear attenuation coefficient. Although the XCOM web database provides information on the linear attenuation of materials, it is based on the assumption of a monochromatic $\mathrm{X}$-ray source, while the actual $\mathrm{X}$-ray source provides a polychromatic bundle of X-rays. Still however, the theoretical predictions, based on this graphical display match the different CT experiments with these materials (Figure 9).

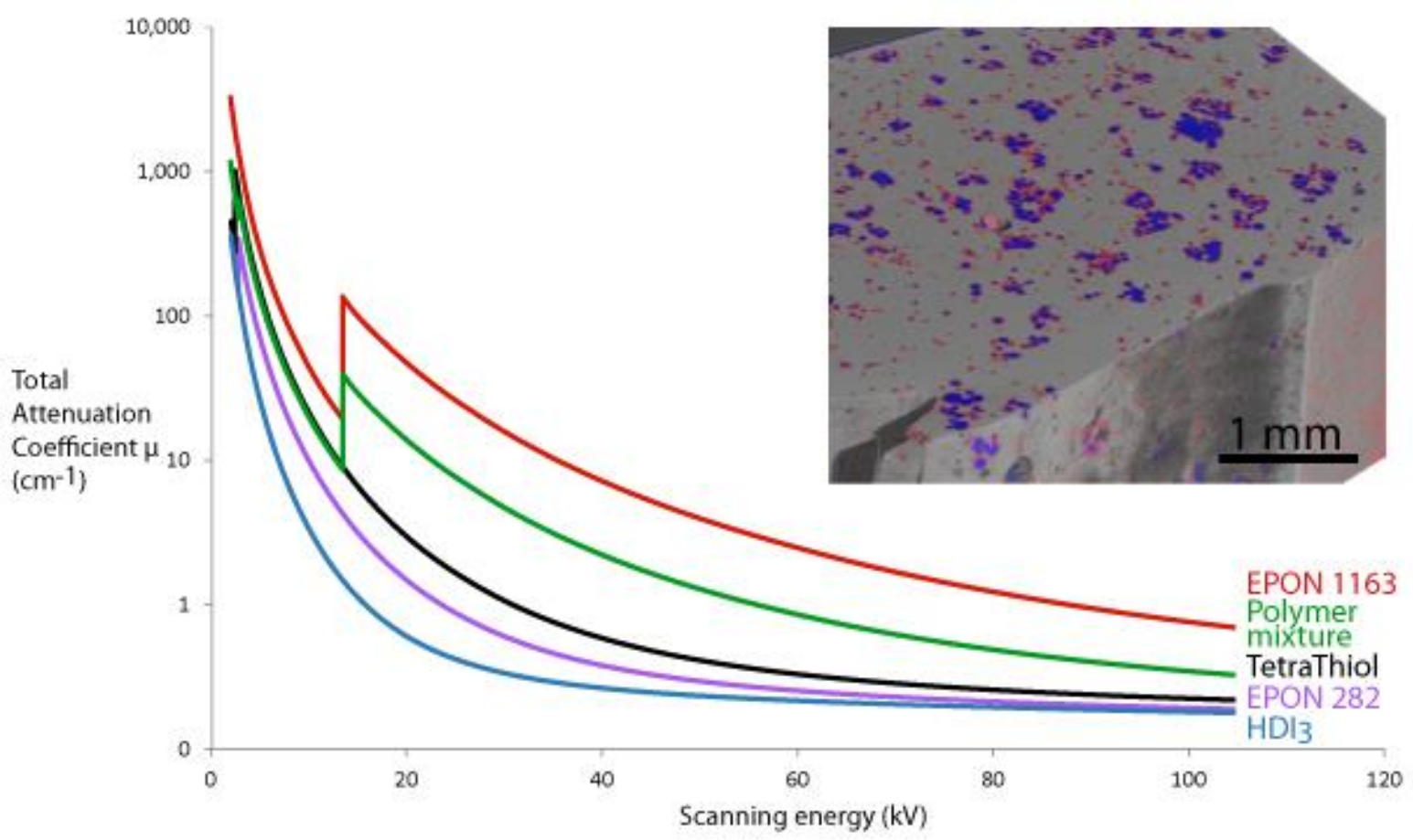

Figure 9. Plot of the total attenuation coefficient of each of the components in the experiment with brominated epoxy, based on the XCOM web database of the National institute of Standards and Technology (NIST), USA. It shows that, using EPON 828 as the epoxy matrix, the $\mathrm{HDI}_{3}$-capsules are nearly indistinguishable at a scanning energy of $100 \mathrm{kV}$, while the TetraThiolcapsules are clearly observable. Using the mixture of the EPON 828 and the EPON 1163 polymer, one can distinguish both capsules from each other, and from the polymer matrix, as shown in the 3D rendering. In this rendering, the blue TetraThiol capsules are partly coagulated, and distinguishable from the smaller pink $\mathrm{HDI}_{3}$ capsules.

\subsection{Leakage experiments}

\subsubsection{Healing agent leakage in epoxy material}

Epoxy samples, containing microcapsules with the TetraThiol healing agent, were scanned before and after induction of a crack. This allows for differential imaging, which was facilitated by using identical scanning parameters in the different $\mu \mathrm{CT}$ scans (1800 projections with an exposure time of $999 \mathrm{~ms}$ each, $\mathrm{X}$-ray source accelerating voltage of $100 \mathrm{kV}$ and an output power of $10 \mathrm{~W}$ ). Because the samples had to be removed from the sample stage between the two scans in order to induce the crack, they 
had to be re-centered on the $\mu \mathrm{CT}$ sample stage prior to the second scan. This resulted in small differences in the distance between the X-ray source and the samples, and thus small differences in image resolution and magnification between subsequent scans. These differences were solved during the processing steps of the differential imaging $[29,30]$. For this, the images with the highest resolution were resized to match the images with the lower resolution. Figure 10 illustrates the concept of differential imaging.

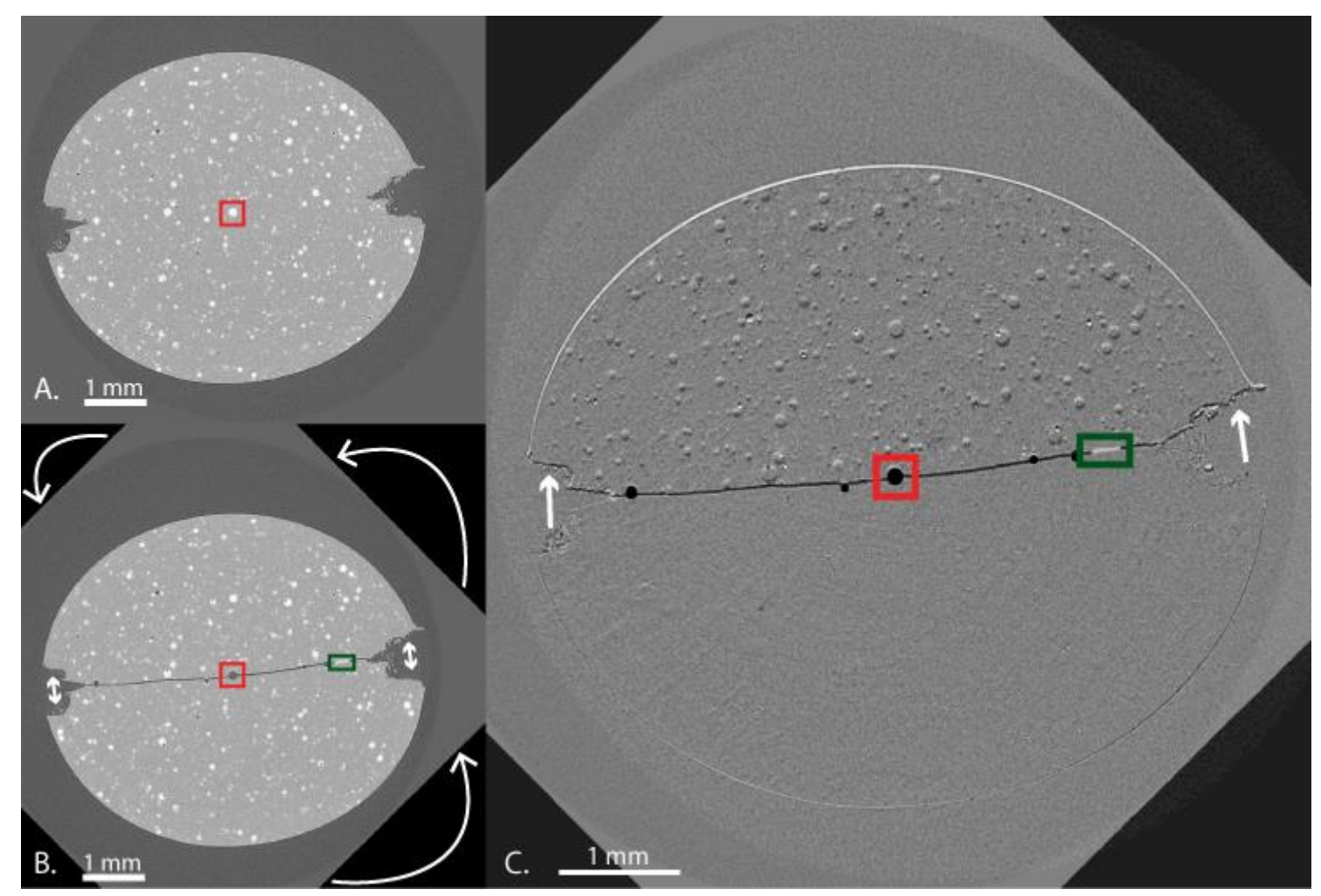

Figure 10: A) horizontal slice through an unbroken epoxy cylinder, containing TetraThiol microcapsules; B) the same slice, however with a crack induced in it. The red square shows a TetraThiol capsule which is now emptied; in the green square healing material is accumulated in the crack; C) differential image between figure B and figure A. Because of the crack opening, the differential imaging step is only successful for one of the sides of the epoxy cylinder.

Figure $10 \mathrm{a}$ is a horizontal slice through an unbroken epoxy cylinder, containing the TetraThiol microcapsules. A red square indicates a microcapsule, clearly distinguishable from the epoxy. Figure $10 \mathrm{~b}$ is a vertical slice through the same epoxy cylinder, at the same height as in Figure 10a, but after the induction of a crack. The arrows indicate the opening of the crack on the one hand, and the rotation of the image on the other hand, so that the material is oriented in the same way as in Figure 10a. Figure 10c shows a slice from the differential image between Figure 10a and 10b. The red square indicates the emptied microcapsules, which is also indicated in Figure 10a and 10b. The green square shows outflow of material in the newly formed crack, originating from a nearby microcapsule. In addition to outflow material and emptied microcapsules, one more feature is very noticeable in the differential image of Figure 10C: only one side of the epoxy cylinder can be perfectly imaged using the differential imaging. This is due to the fact that the crack formation creates a relative movement between the two halves: differential imaging is only successful for one of the halves, since the other one has moved relatively to the primary set-up. However, this does not interfere with the analysis, since the differential imaging step will always include the crack formation as well as the outflow of healing 
agents, which was confirmed by doing the differential imaging step twice: once for each half of the sample.

The emptied capsules, together with the crack, and the healing agent that flowed into the crack, could be thresholded in Octopus Analysis, after which a 3D render was made in VGStudio ${ }^{\circledR}$ MAX. Three different sample configurations with respectively 5, 10 and $15 \mathrm{wt} \%$ of microcapsules were selected to visualize the effect of the microcapsule concentration on the leakage of healing agents. These experimental set-ups are similar to the ones investigated by Hillewaere et al. (2014), however, the volume of the epoxy bulk material is reduced, so that leakage of the healing agents could be investigated in-situ with micro-CT, at an appropriate resolution to distinguish the microcapsules and the induced crack.

Figure 11 shows 3D renderings of three of the investigated samples. The empty microcapsules, which released their healing agent, and the open volume, created by the crack, which have the same grey values, are tagged in red. Note that it was not possible to tag the crack in the sample with $5 \mathrm{wt} \%$ capsules. The distinguishable outflowed healing agent is tagged in blue. This figure illustrates some of the difficulties that arise in the post processing of the $\mu \mathrm{CT}$ images. In the case of the sample with 5 wt\% of capsules, the uncontrolled crack opening was too close to the resolution of the scan to allow its segmentation by grey value thresholding. As a consequence, it was only possible to differentiate the microcapsules which opened, situated in the crack. However, visually, it was clear that a significant amount of the crack was filled with healing agent. In spite of this, the experiments showed some clear trends. The amount of healing agent flowing out, which could be visualized on the $\mu \mathrm{CT}$ scans, increased according to the increasing wt\% of the capsules in the epoxy matrix: the denser the capsules are distributed, the more capsules will be opened up by the propagating crack and thus the more outflow material will be visible. However, not all broken capsules were surrounded by healing agent. This might be due to the roughness of the crack plane which contains plastic zones, tails in the wake of microcapsules, hackle marking and sub-surface microcracks with a size of hundred nanometers [21]. The capillarity force drives the healing agent through the roughness surface to a located zones. It was expected that the healing agent went to the crack tip where the crack opening was small, but there could be some other located areas where the healing agent was accumulated. In addition, the subsurface microcracks could also retain healing agent. Healing agents within sub-surface microcracks, with a crack opening smaller than the resolution of the scan, will remain undetected in the $\mu \mathrm{CT}$ scan. As expected, when the amount of microcapsules increases, the amount of healing agent detected as outflow increases at least qualitative. In the case of the experiment with $15 \mathrm{wt} \%$ of microcapsules, it was possible to clearly distinguish the healing agents at the crack tip, which typically has a smaller crack opening than the remainder of the crack. More microcapsules are present in this case, delivering more healing agent to this small opening, making it easier to detect and segment in $\mu \mathrm{CT}$ images.

The visualization of the distribution of microcapsules and the behavior of the outflow give a valuable information about the self-healing system with one or two types of microcapsules embedded in an epoxy matrix. That information is necessary for the design of new systems and models. 

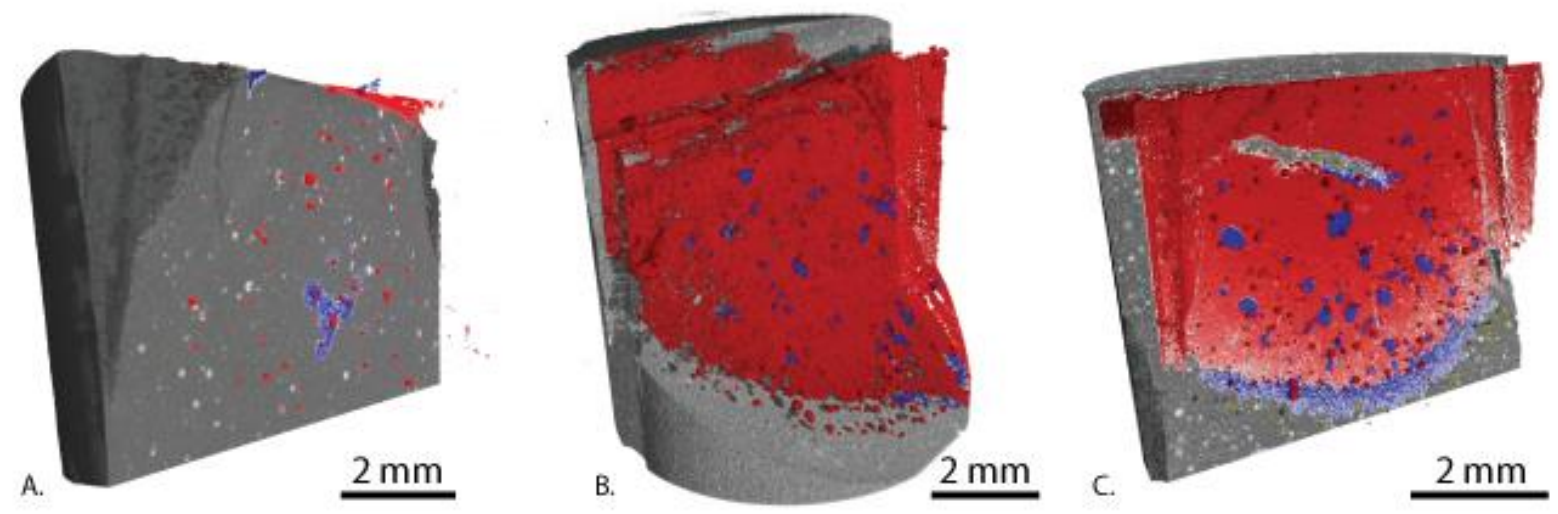

Figure 11: Polymer samples with 5 wt\% (A), 10 wt\% (B) and 15 wt\% (C) microcapsule content respectively. Within these samples a crack is induced, leading to outflow of healing agents which could be visualised through differential imaging. The figures show empty capsules (in red) within the open volume of the newly created crack (red in the case of figure B and C), as well as healing agents that partly fill the crack (blue).

\subsubsection{Healing agent leakage in concrete}

The experiments in which the outflow of healing agents is investigated within concrete cubes were also performed on the HECTOR setup. Based on the same concept of differential imaging, two scans were made per experiment: one before the glass capsules containing the healing agents were broken, and one after. In these experiments, differential imaging is once again only successful for one of the two concrete blocks next to the artificial crack. This however does not interfere with the analysis of the outflow of healing agents within the crack, since the crack itself is included in the differential imaging step at all time, as well as the healing agents filling the cracks. Figure 12 illustrates the process in which one of the glass tubes within the two concrete blocks, separated by an artificial crack, is broken. The downward movement of the small concrete prism (Figure 12B) causes the glass tube to break and part of the healing agent in the capsule to flow into the artificial crack. 


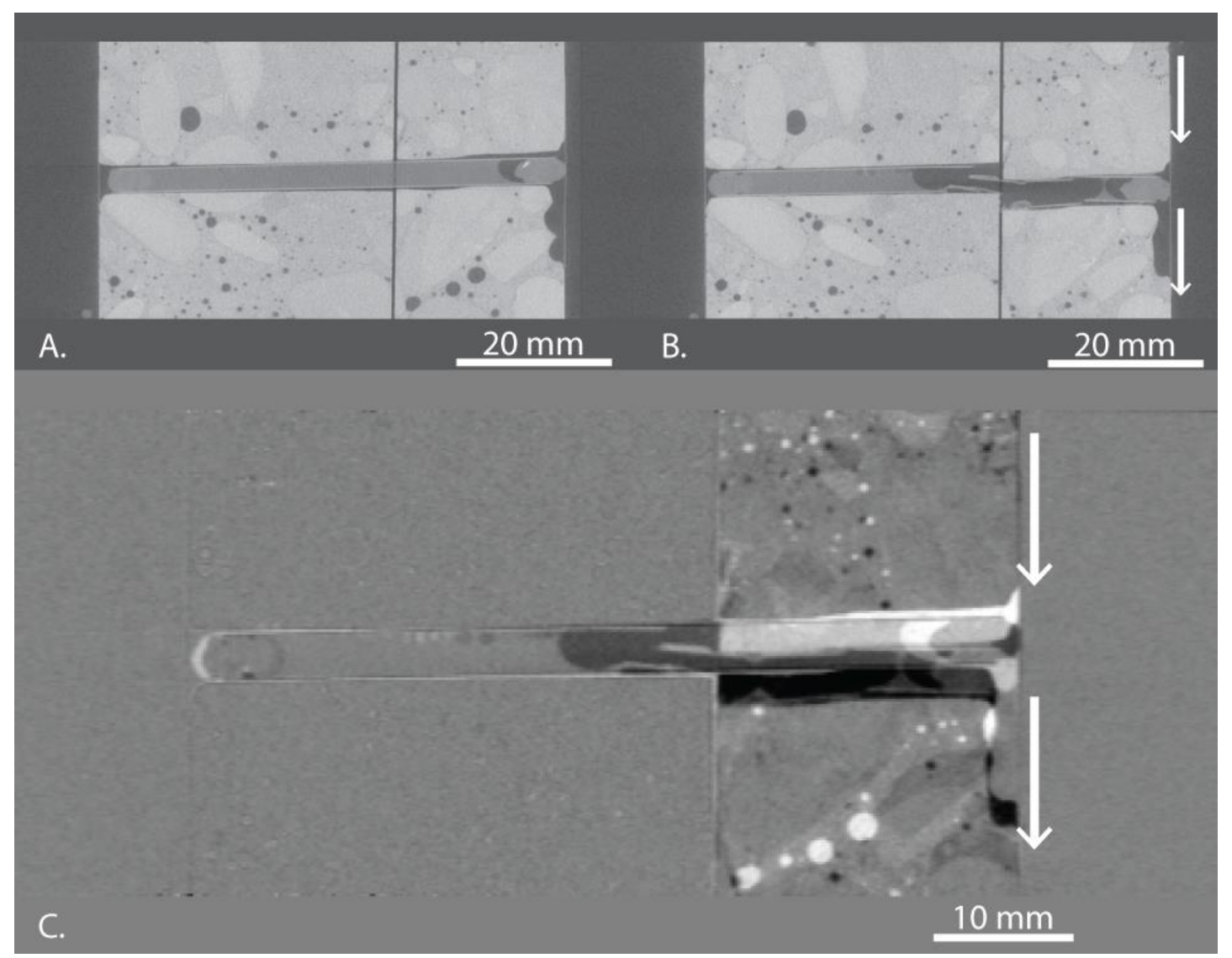

Figure 12: Vertical slices through the set-up in which two concrete prisms are separated by an artificial crack, with a COD of $150 \mu \mathrm{m}$. A) Illustrates the set-up in its initial state, prior to breakage of the glass capsule. B) Shows the set-up after the smaller concrete prism has been moved downwards, thereby breaking the glass tube, causing the healing agents to flow out into the crack. $C$ ) is the differential image from $A$ and $B$, in which the processing is effective only for the large concrete prism. Dark areas are those where in figure $B$ material has been replaced by less attenuating material respectively to the same area in figure $A$ (such as air compared to cement matrix or healing agents). Vice versa, bright areas represent those in which in figure $\mathrm{B}$ material has been replaced by more attenuating material, compared to the same area in figure $\mathrm{A}$.

The experiment illustrated in 2D in Figure 12, and in 3D in Figure 13, was further analysed using "Octopus Analysis", with the emphasis on the amount of healing agent distributed within the sample. Prior to breakage of the glass capsules (Figure 13A), the two capsules contained a total volume of healing agents of $760 \mathrm{~mm}^{3}$, as calculated from the $\mu \mathrm{CT}$ images. Subsequently, the glass capsules were broken by a slight tap on the smallest concrete prism. Part of the healing agents leaked out of the glass capsules, however, more than half ( $398 \mathrm{~mm}^{3}$, as calculated from the $\mu \mathrm{CT}$ images) stayed behind in the parts of the capillaries furthest removed from the crack (figure 13b). Healing agents were also found within the artificial crack (Figure 13C). However, here only a volume of $23 \mathrm{~mm}^{3}$ (calculated from the $\mu \mathrm{CT}$ images) of healing agents was found, which primarily is linked to one of both capillaries. This confirms that the insertion of a water-based accelerator in the second capillary has little to no effect. This fluid is absorbed by the concrete (a result which could visually be confirmed after the test). Since concrete is known to have a wide pore size distribution, it is not unlikely that part of these fluids are to be found in pores with a size smaller than the resolution of the scan $(46.3 \mu \mathrm{m})$, leaving these fluids therefore undetectable on the $\mu \mathrm{CT}$ scans. 


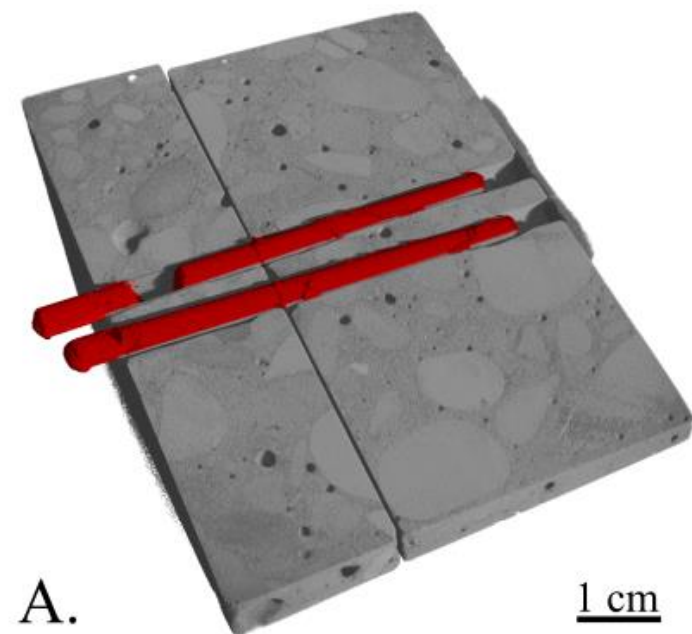

A.

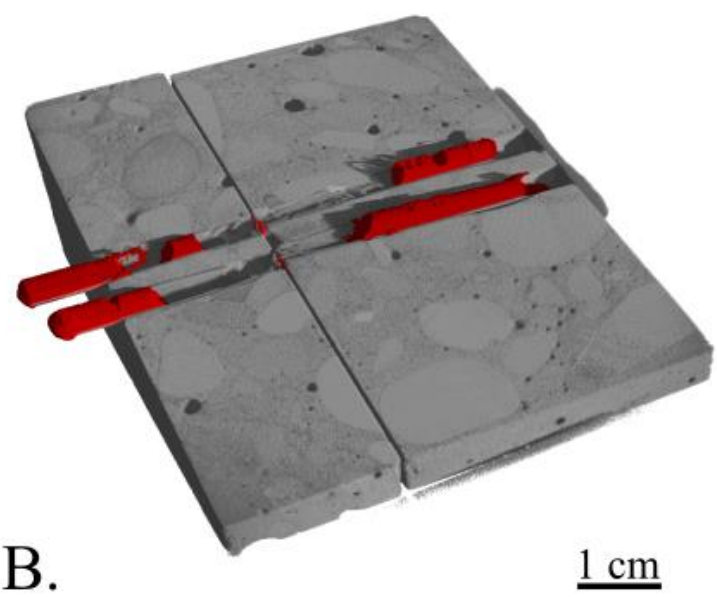

C. $1 \mathrm{~cm}$

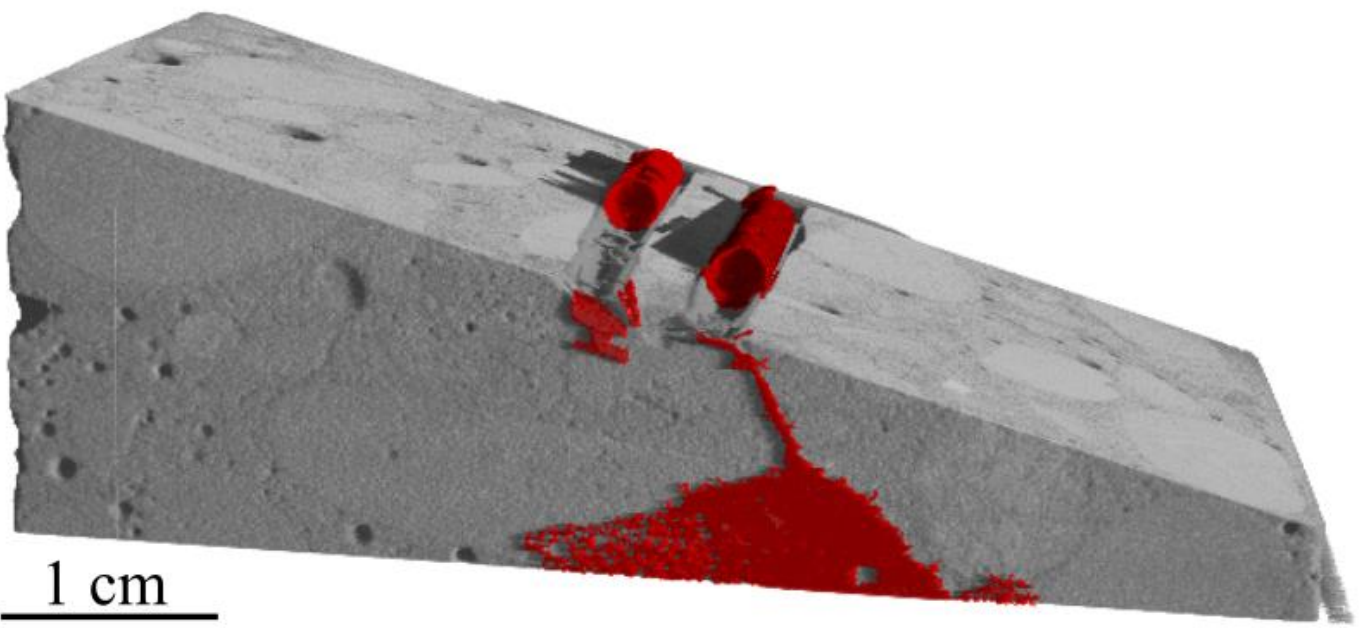

Figure 13: 3D illustration of the healing agents (red) in the different steps of the experiment: $A$ ) in the beginning of the experiment, when the glass tubes are still intact; B) after the movement of the smallest concrete prism has broken the glass capsules, thereby releasing part of the healing agents; C) a side view of the leakage of healing agents within the artificial crack.

In a second experiment, in which the glass capsule content was calculated, based on the $\mu C T$ images, to $598 \mathrm{~mm}^{3}$ prior to breakage of the capillaries, again a calculated volume of only $23 \mathrm{~mm}^{3}$ of healing agents was found within the artificial crack, while a volume of $334 \mathrm{~mm}^{3}$ of healing agents remained within the glass tubes. In this experiment, the water-based accelerator again shows no leakage within the artificial crack. Generally, the experiments show that leakage from the glass tubes is only successful in the area of breakage. Further away, the capillary effect in the glass capsules prevents the fluids from coming out. Also, under these conditions, gravity forces dominate over capillary effects in the artificial crack. The healing agents fill the crack irregularly and incomplete.

\section{Conclusions}

The effectiveness and efficiency of extrinsic self-healing systems are critically determined by the distribution and the mechanical behaviour of the healing agent carriers that are incorporated into the material. While non-destructive, high resolution 3D imaging of the systems in question can provide important information on such materials' microstructure, relatively few studies have explored such techniques, especially with regard to in-situ tests of the healing mechanics. In this work, we 
demonstrate the use of $\mu \mathrm{CT}$ in the advanced characterization of extrinsic self-healing systems, which yields information complementary to mechanical testing and traditional 2D imaging techniques.

In the particular case of polymer-based self-healing systems, it is important to be able to measure the 3D distribution of the individual microcapsules in the polymer matrix. We demonstrated that $\mu \mathrm{CT}$ measurements can serve to discern between the cases of coagulated and homogenously spread capsules in an epoxy matrix. The difference in distribution may lead to inconsistencies in healing efficiency. Another important factor in this regard is the debonding of capsules, which will prevent breaking of the capsules and leakage with subsequent reaction of the healing agents. We show that $\mu C T$ scans allow to investigate the capsules in their native state in 3D (i.e. without destructive sampling), revealing which capsules are debonded. Despite the strong advantages of $\mu C T$ scanning, remaining issues are, on the one hand, obtaining sufficient contrast between some healing agents (in this case $\mathrm{HDI}_{3}$-capsules) and the matrix, which was attempted by modifying the polymer matrix composition, and on the other hand a quantification of capsule coagulation.

Next to the visualization of the distribution and debonding of microcapsules, we present two experiments which demonstrate how $\mu \mathrm{CT}$ scans can be used to investigate healing mechanisms in-situ. We show that the outflow of healing agents in a polymer and a concrete matrix can be visualized and quantified, with limitations related to the $\mu \mathrm{CT}$ set-up, allowing to investigate how much of the fluid flows out of the capsules or remains behind. This may lead to optimization of the geometry of the carriers, and helps to explain the behaviour of different self-healing materials, for example as a function of the amount of capsules. Further research needs to be conducted on how to perform and link higher resolution (2D or 3D) imaging experiments to the results at the presented scale, in order to take sub-resolution fractures into account. Furthermore, fast $\mu \mathrm{CT}$ scans, performed in the order of seconds, are being developed both at synchrotrons [15] and in more conventional laboratories [31], which may in the future allow to obtain much-needed dynamic insight on breakage of the carriers and the leakage and reaction of the healing agents. The experiments herein presented illustrate the use of non-destructive 3D imaging techniques to enhance our understanding of the microstructural performance of these engineered materials.

\section{Acknowledgements}

The authors would like to acknowledge the financial support from the Strategic Initiative Materials (SIM)-Flanders, supported by IWT, for both SBO programmes SEPOCOM (SElf-healing concepts in thermoset POlymers and COMposites) and SECEMIN (SElf-healing mechanisms and concepts for CEmentitious and MINeral building materials), under the program SHE (Engineered Self-Healing materials) (SIM 2009-1). Also the Agency for Promotion of Innovation by Science and Technology in Flanders, Belgium (IWT) is acknowledged for the PhD scholarship of T. Bultreys.

\section{Highlights}

- $\quad \mu C T$ imaging allows for the analysis of microcapsule distribution patterns in self-healing materials.

- $\quad \mu \mathrm{CT}$ allows for qualitative and quantitative measurements of healing agent release from carriers in self-healing materials.

- Experimental setups can be optimized by changing chemical compounds in the system to ensure maximum quality imaging. 


\section{Artwork (titles + image size)}

Figure $1=$ 'Chemical reaction between $\mathrm{HDI}_{3}$ and TetraThiol' 1.5 column fitting

Figure 2 = 'Schematic representation of TDCB sample' 1 column fitting

Figure 3 = 'Chemical structure of epoxy resin EPON 1163' 1 column fitting

Figure 4 = 'Setup of healing agent outflow experiment in epoxy samples' 1 column fitting

Figure 5 = 'Setup of healing agent outflow experiment in cementitious material' 1 column fitting

Figure 6 = 'Distribution of microcapsules in epoxy' 1 column fitting

Figure 7 = 'Debonded microcapsules in an epoxy sample' 1 column fitting

Figure $8=$ '3D rendering of crack surface in a fractured TDCB sample' 1.5 column fitting

Figure $9=$ 'Plot of total attenuation coefficient of different components in brominated epoxy sample' 1.5 column fitting

Figure 10 = 'Differential imaging of healing agent outflow in epoxy samples' 1.5 column fitting

Figure 11 = 'Outflow of healing agent in epoxy samples' 1.5 column fitting

Figure 12 = 'Differential imaging of healing agent outflow in cementitious material' 1.5 column fitting

Figure 13 = 'Outflow of healing agent in cementitious material' 1.5 column fitting

Table 1 = 'Concrete composition for healing agent outflow experiments'

\section{References}

[1] X.K.D. Hillewaere, F.E. Du Prez, Fifteen Chemistries for Autonomous External Self-Healing Polymers and Composites, Prog. Polym. Sci. 49 (2015) 121-153. doi:10.1016/j.progpolymsci.2015.04.004.

[2] Y.C. Yuan, M.Z. Rong, M.Q. Zhang, Preparation and characterization of microencapsulated polythiol, Polymer (Guildf). 49 (2008) 2531-2541. doi:10.1016/j.polymer.2008.03.044.

[3] M.D. Hager, P. Greil, C. Leyens, S. van der Zwaag, U.S. Schubert, Self-Healing Materials, Adv. Mater. 22 (2010) 5424-5430. doi:10.1002/ adma201003036.

[4] S. Billiet, X.K.D. Hillewaere, R.F.A. Teixeira, F.E. Du Prez, Chemistry of crosslinking processes for self-healing polymers., Macromol. Rapid Commun. 34 (2013) 290-309. doi:10.1002/marc.201200689.

[5] S. Van der Zwaag, Self healing materials, an alternative approach to 20 centuries of material science, 2007.

[6] B.J. Blaiszik, S.L.B. Kramer, S.C. Olugebefola, J.S. Moore, N.R. Sottos, S.R. White, Self-Healing Polymers and Composites, Annu. Rev. Mater. Res. 40 (2010) 179-211. doi:10.1146/annurevmatsci-070909-104532. 
[7] K. Van Tittelboom, N. De Belie, Self-Healing in Cementitious Materials - A Review, Materials (Basel). 6 (2013) 2182-2217. doi:10.3390/ma6062182.

[8] R.P. Wool, Self-healing materials: a review, Soft Matter. 4 (2008) 400-418. doi:10.1039/b711716g.

[9] Z. Yang, J. Hollar, X. He, X. Shi, Laboratory Assessment of a Self-Healing Cementitious Composite, Transp. Res. Rec. J. Transp. Res. Board. 2142 (2010) 9-17. doi:10.3141/2142-02.

[10] S.H. Cho, S.R. White, P. V. Braun, Self-Healing Polymer Coatings, Adv. Mater. 21 (2009) 645649. doi:10.1002/adma.200802008.

[11] M.W. Keller, S.R. White, N.R. Sottos, A Self-Healing Poly(Dimethyl Siloxane) Elastomer, Adv. Funct. Mater. 17 (2007) 2399-2404. doi:10.1002/adfm.200700086.

[12] K.S. Toohey, N.R. Sottos, J. a Lewis, J.S. Moore, S.R. White, Self-healing materials with microvascular networks., Nat. Mater. 6 (2007) 581-5. doi:10.1038/nmat1934.

[13] M.R. Kessler, N.R. Sottos, S.R. White, Self-healing structural composite materials, Compos. Part A Appl. Sci. Manuf. 34 (2003) 743-753. doi:10.1016/S1359-835X(03)00138-6.

[14] J. Vlassenbroeck, M. Dierick, B. Masschaele, V. Cnudde, L. Van Hoorebeke, P. Jacobs, Software tools for quantification of X-ray microtomography at the UGCT, Nucl. Instruments Methods Phys. Res. Sect. A Accel. Spectrometers, Detect. Assoc. Equip. 580 (2007) 442-445. doi:10.1016/j.nima.2007.05.073.

[15] E. Maire, P.J. Withers, Quantitative X-ray tomography, Int. Mater. Rev. 59 (2014) 1-43. doi:10.1179/1743280413Y.0000000023.

[16] V. Cnudde, M.N. Boone, High-resolution X-ray computed tomography in geosciences: A review of the current technology and applications, Earth-Science Rev. 123 (2013) 1-17. doi:10.1016/j.earscirev.2013.04.003.

[17] S.D. Mookhoek, S.C. Mayo, A.E. Hughes, S.A. Furman, H.R. Fischer, S. van der Zwaag, Applying SEM-Based X-ray Microtomography to Observe Self-Healing in Solvent Encapsulated Thermoplastic Materials, Adv. Eng. Mater. 12 (2010) 228-234. doi:10.1002/adem.200900289.

[18] K. Van Tittelboom, N. De Belie, D. Van Loo, P. Jacobs, Self-healing efficiency of cementitious materials containing tubular capsules filled with healing agent, Cem. Concr. Compos. 33 (2011) 497-505. doi:10.1016/j.cemconcomp.2011.01.004.

[19] G.P. McCombe, J. Rouse, R.S. Trask, P.J. Withers, I.P. Bond, X-ray damage characterisation in self-healing fibre reinforced polymers, Compos. Part A Appl. Sci. Manuf. 43 (2012) 613-620. doi:10.1016/j.compositesa.2011.12.020.

[20] Á. García, Self-healing of open cracks in asphalt mastic, Fuel. 93 (2012) 264-272. doi:10.1016/j.fuel.2011.09.009.

[21] E.N. Brown, S.R. White, N.R. Sottos, Microcapsule induced toughening in a self-healing polymer composite, J. Mater. Sci. 39 (2004) 1703-1710. doi:10.1023/B:JMSC.0000016173.73733.dc.

[22] X.K.D. Hillewaere, R.F.A. Teixeira, L.-T.T. Nguyen, J. a. Ramos, H. Rahier, F.E. Du Prez, Autonomous Self-Healing of Epoxy Thermosets with Thiol-Isocyanate Chemistry, Adv. Funct. Mater. 24 (2014) 5575-5583. doi:10.1002/adfm.201400580.

[23] L.-T.T. Nguyen, X.K.D. Hillewaere, R.F.A. Teixeira, O. van den Berg, F.E. Du Prez, Efficient microencapsulation of a liquid isocyanate with in situ shell functionalization, Polym. Chem. 6 (2015) 1159-1170. 
[24] E.N. Brown, N.R. Sottos, S.R. White, Fracture Testing of a Self-Healing Polymer Composite, Exp. Mech. 42 (2002) 372-379.

[25] D. Wildenschild, A.P. Sheppard, X-ray imaging and analysis techniques for quantifying porescale structure and processes in subsurface porous medium systems, Adv. Water Resour. 51 (2013) 217-246. doi:10.1016/j.advwatres.2012.07.018.

[26] L. Brabant, J. Vlassenbroeck, Y. De Witte, V. Cnudde, M.N. Boone, J. Dewanckele, et al., Threedimensional analysis of high-resolution X-ray computed tomography data with Morpho+., Microsc. Microanal. 17 (2011) 252-263. doi:10.1017/S1431927610094389.

[27] B. Masschaele, M. Dierick, D. Van Loo, M.N. Boone, L. Brabant, E. Pauwels, et al., HECTOR: A 240kV micro-CT setup optimized for research, J. Phys. Conf. Ser. 463 (2013) 012012. doi:10.1088/1742-6596/463/1/012012.

[28] B.C. Masschaele, V. Cnudde, M. Dierick, P. Jacobs, L. Van Hoorebeke, J. Vlassenbroeck, UGCT: New X-ray radiography and tomography facility, Nucl. Instruments Methods Phys. Res. Sect. A Accel. Spectrometers, Detect. Assoc. Equip. 580 (2007) 266-269. doi:10.1016/j.nima.2007.05.099.

[29] M.A. Boone, T. De Kock, T. Bultreys, G. De Schutter, P. Vontobel, L. Van Hoorebeke, et al., 3D mapping of water in oolithic limestone at atmospheric and vacuum saturation using $\mathrm{X}$-ray micro-CT differential imaging, Mater. Charact. 97 (2014) 150-160. doi:10.1016/j.matchar.2014.09.010.

[30] R.A. Ketcham, G.J. Iturrino, Nondestructive high-resolution visualization and measurement of anisotropic effective porosity in complex lithologies using high-resolution X-ray computed tomography, J. Hydrol. 302 (2005) 92-106. doi:10.1016/j.jhydrol.2004.06.037.

[31] T. Bultreys, M.A. Boone, M.N. Boone, T. De Schryver, B. Masschaele, L. Van Hoorebeke, et al., Fast laboratory-based micro-computed tomography for pore-scale research: illustrative experiments and perspectives on the future, Adv. Water Resour. (2015). 